\title{
Sustainable Production of Microbial Lipids from Lignocellulosic Biomass Using Oleaginous Yeast Cultures
}

\author{
Jung-Eun Lee ${ }^{1 *}$, Praveen V. Vadlani, ${ }^{1,2}$ Doohong Min ${ }^{3}$ \\ ${ }^{1}$ Bioprocessing and Renewable Energy Laboratory, Grain Science and Industry, Kansas State University, \\ Manhattan, KS, USA \\ ${ }^{2}$ Department of Chemical Engineering, Kansas State University, Manhattan, KS, USA \\ ${ }^{3}$ Department of Agronomy, Kansas State University, Manhattan, KS, USA \\ Email: *ljungeunlee2@gmail.com
}

How to cite this paper: Lee, J.-E., Vadlani, P.V. and Min, D. (2017) Sustainable Production of Microbial Lipids from Lignocellulosic Biomass Using Oleaginous Yeast Cultures. Journal of Sustainable Bioenergy Systems, 7, 36-50. https://doi.org/10.4236/jsbs.2017.71004

Received: March 1, 2017

Accepted: March 21, 2017

Published: March 24, 2017

Copyright (c) 2017 by authors and Scientific Research Publishing Inc. This work is licensed under the Creative Commons Attribution International License (CC BY 4.0).

http://creativecommons.org/licenses/by/4.0/

\section{(c) (i) Open Access}

\begin{abstract}
Microbial lipids derived from oleaginous yeast could be a promising resource for biodiesel and other oleochemical materials. The objective of this study was to develop an efficient bioconversion process from lignocellulosic biomass to microbial lipids using three types of robust oleaginous yeast: $T$. oleaginosus, $L$. starkeyi, and C. albidus. Sorghum stalks and switchgrass were utilized as feedstocks for lipid production. Among oleaginous yeast strains, T. oleaginous showed better performance for lipid production using sorghum stalk hydrolysates. Lipid titers of $13.1 \mathrm{~g} \cdot \mathrm{L}^{-1}$ were achieved by $T$. oleaginosus, using sorghum stalk hydrolysates with lipid content of $60 \%\left(\mathrm{wt} \cdot \mathrm{wt}^{-1}\right)$ and high lipid yield of $0.29 \mathrm{~g} \cdot \mathrm{g}^{-1}$, which was substantially higher than the value reported in literature. Assessment of overall lipid yield revealed a total of $14.3 \mathrm{~g}$ and $13.3 \mathrm{~g} \mathrm{li}$ pids were produced by $T$. oleaginosus from $100 \mathrm{~g}$ of raw sorghum stalks and switchgrass, respectively. This study revealed that minimization of sugar loss during pretreatment and selection of appropriate yeast strains would be key factors to develop an efficient bioconversion process and improve the industrial feasibility in a lignocellulose-based biorefinery.
\end{abstract}

\section{Keywords}

Trichosporon oleaginosus, Lipomyces starkeyi, Cryptococcus albidus, Lignocellulosic Hydrolysates, Sorghum Stalks, Switchgrass

\section{Introduction}

Microbial lipids are promising candidates for replacing traditional oil sources in the production of biodiesel, oleo-chemicals, and nutraceuticals, due to similar 
chemical composition and energy value [1] [2]. A research estimated that cost of microbial lipids would be $\$ 3.4 \mathrm{~kg}^{-1}$, excluding a feedstock price, and $\$ 5.5 \mathrm{~kg}^{-1}$, including glucose as a feedstock [3], whereas cost of vegetable oil is $\$ 1.5-3 \mathrm{~kg}^{-1}$ less [4]. A supply of low-cost carbohydrates for microbes is required for sustainable and cost-effective production of bio-based lipids.

Lignocellulosic biomass, such as agricultural residues and woody crops, is a strong alternative substrate for microbial lipid production due to their abundance, low-cost investment, and high content of polysaccharides (up to 75\%) [5] [6]. More than $90 \%$ of global production of plant biomass is lignocellulosic biomass, which is composed of cellulose, hemicellulose, and lignin [7]. Recalcitrant lignocellulosic biomass is converted to monomer sugars via pretreatment and enzymatic hydrolysis [8]. Many pretreatment methods maximize exposure of carbohydrate polymers (cellulose and hemicellulose) with effective separation of the lignin portion, which is an interference biopolymer during bioconversion [9] [10]. Among many attempts, an alkaline pretreatment is known to efficiently remove lignin from plant cell wall structures [11]. Cellulose and hemicellulose are depolymerized to monosaccharides by synergetic actions of enzyme mixtures [12]. The most abundant monomer sugars derived from lignocellulosic biomass are D-glucose, since cellulose represents $70 \%$ of total plant cell walls, repeating the $\beta$ - $(1 \rightarrow 4)$ glycosidic bond [13]. However, species of lignocellulosic-based monomer sugars depend on biomass types.

Several challenges remain for successful bioconversion of lignocellulosic biomass to microbial lipids. A broad array of monomer sugars is generated from lignocellulosic biomass including glucose, xylose, mannose, and arabinose. Typically, the ratio of hexoses to pentoses ranges from $1.5: 1$ to $3: 1$ [14]. However, some species of microbes only utilize limited types of monomer sugars as carbon sources. In addition, a number of by-products, such as furans, aldehydes, and organic acids, are generated during pretreatment and enzymatic hydrolysis [15] [16] [17] [18]. These compounds are known to inhibit microbes' growth and product formation during fermentation. Acetic acid, especially, is an inevitable compound, which are normally released from acetyl groups of hemicellulose during enzymatic hydrolysis [19]. Acetic acid adversely affects the integrity of the cell membrane by accumulating in deprotonated form [20].

Oleaginous yeast, which has an inherent ability to accumulate lipids from $20 \%$ to $70 \%$ as a percentage of cell dry weight, offers many advantages to overcome challenges associated with lignocellulose-based lipid production [21] [22]. Basidiomycetous yeast species such as Cryptococcus albidus and Trichosporon oleaginosus are known to enable use of a variety of carbon sources, and can be grown without supplemented costly nutrients [23] [24]. In addition, oleaginous yeast cultures are insusceptible to toxic compounds compared with bacteria. Previous studies reported some types of oleaginous yeast consumed weak acids, including acetic acid and formic acid [25] [26].

In this study, production of lignocellulose-based microbial lipids was investigated using three oleaginous yeast cultures: Trichosporon oleaginosus 
ATCC20509, Lipomyces starkeyi ATCC 56304, and Cryptococcus albidus ATCC10672. Sorghum stalks and switchgrass, which are typical bio-energy crops, were utilized as sugar suppliers for microbial lipid production. In addition, fermentation performance of $T$. oleaginosus, L. starkeyi, and $C$. albidus were evaluated using sorghum stalks and switchgrass hydrolysates. To our knowledge, C. albidus ATCC 10672 has not previously been evaluated for lipid production using lignocellulosic hydrolysates. Also, overall yield of microbial lipids from raw biomass was studied to evaluate the lipid production process.

\section{Materials and Methods}

\subsection{Lignocellulosic Biomass and Compositional Analysis}

Sorghum stalks were obtained from Texas A\&M University, College Station, Texas, and ground by Mesa Associate Inc., Knoxville, Tennessee. Switchgrass was obtained from the Kansas State University agronomy farm, Manhattan, Kansas, and ground at a size of less than $1 \mathrm{~mm}$, using a Tomas-Wiley laboratory mill (Model 4). Biomass composition was determined following the protocol of NREL/TP-510-42618 [27].

\subsection{Pretreatment and Enzymatic Hydrolysis of Lignocellulosic Biomass}

A schematic diagram of the process for lignocellulosic hydrolysate preparation was shown in Figure 1.

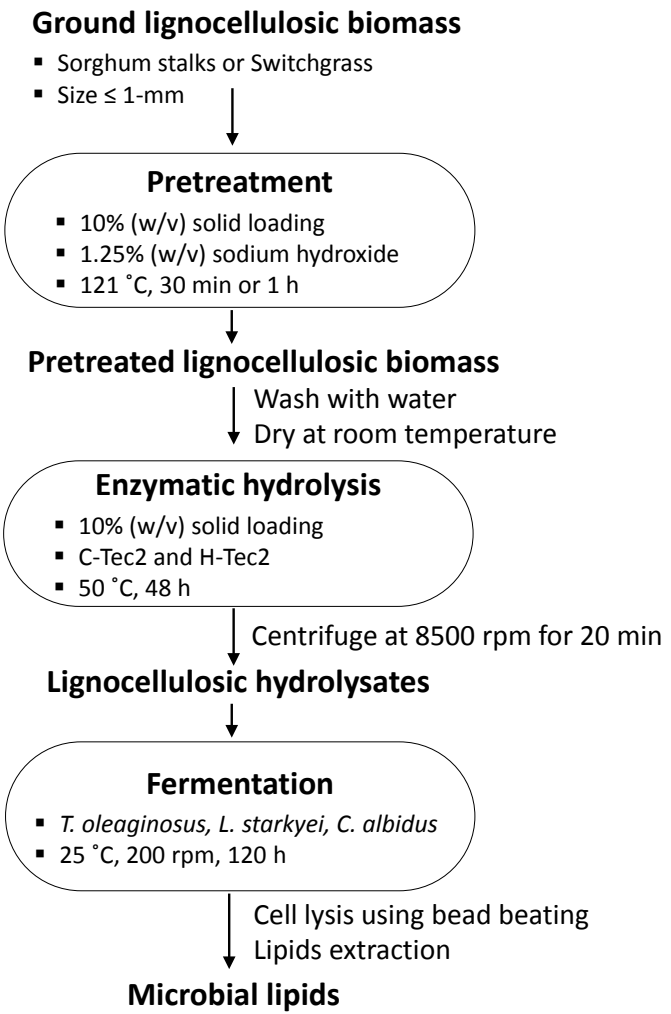

Figure 1. Schematic diagram of microbial lipid production from lignocellulosic biomass. 
Pretreatment and hydrolysis conditions for each lignocellulosic biomass were optimized in our lab and it was followed in this study for lipid production [28]. The ground biomass was mixed with $1.25 \%\left(\mathrm{w} \cdot \mathrm{v}^{-1}\right)$ sodium hydroxide $(\mathrm{NaOH})$, at the rate of $10 \%\left(\mathrm{w} \cdot \mathrm{v}^{-1}\right)$ solid loading, in a $500 \mathrm{~mL}$ flask for pretreatment. Sorghum stalks and switchgrass were pretreated at $121^{\circ} \mathrm{C}$ for $30 \mathrm{~min}$ and $1 \mathrm{~h}$, respectively. The pretreated biomass was washed with an abundant amount of water until the residue of $\mathrm{NaOH}$ was completely removed; about $2 \mathrm{~L}$ of water was used for $5 \mathrm{~g}$ of pretreated biomass. The pretreated biomass after washing process was dried at room temperature for five days. The pretreated biomass was mixed with $50 \mathrm{mM}$ of a citrate buffer $(\mathrm{pH} 4.8)$, at the rate of $5 \%\left(\mathrm{w} \cdot \mathrm{v}^{-1}\right)$ solid loading, for the enzymatic hydrolysis. Commercial cellulolytic (Cellic C-Tec2) and hemicellulotyic (Cellic H-Tec2) enzymes, which were obtained from Novozymes Inc., Franklinton, North Carolina, were added into the pretreated biomass slurry at the rate of $5.4 \%$ and $0.6 \%\left(\mathrm{w} \cdot \mathrm{v}^{-1}\right)$ of biomass, respectively. Enzymatic hydrolysis was conducted in the shaking incubator (Innova 4300, New Brunswick Scientific, NJ) at $50^{\circ} \mathrm{C}$ and $140 \mathrm{rpm}$ for $48 \mathrm{~h}$. The sorghum stalk and switchgrass hydrolysates, which were supernatant after enzymatic hydrolysis, were harvested via centrifugation (Sorvall Super T21, Thermo Fisher Scientific Inc., Waltham, MA, USA) at $8500 \mathrm{rpm}$ and $25^{\circ} \mathrm{C}$ for $20 \mathrm{~min}$.

\subsection{Yeast Strains, Medium, and Culture Conditions}

Trichosporon oleaginosus ATCC 20509, Lipomyces starkeyi ATCC 56304, and Cryptococcus albidus ATCC 10672 were purchased from the American Type Culture Collection (ATCC, Manassas, VA, USA), and cultivated in a yeast mold broth (YM broth, Difco, Detroit, MI, USA) at $25^{\circ} \mathrm{C}$ and $200 \mathrm{rpm}$ for $72 \mathrm{hr}$. All yeast cultures were preserved in $\mathrm{YM}$ agar plates at $4^{\circ} \mathrm{C}$, and transferred to fresh plates once a month.

\subsection{Fermentation Conditions}

Starter cultures of all yeast strains were begun by inoculating a single colony from a YM agar plate. T. oleaginosus, L. starkeyi, and C. albidus were grown in a YM broth at $25^{\circ} \mathrm{C}$ and $200 \mathrm{rpm}$ for $12 \mathrm{~h}$, and cells were transferred into a $500 \mathrm{~mL}$ shake flask containing $100 \mathrm{~mL}$ of fermentation media. Sorghum stalks and switchgrass hydrolysates, containing a total of $50 \mathrm{~g} \cdot \mathrm{L}^{-1}$ sugars, were utilized as carbon sources for lipid production. Nitrogen source of yeast extract $\left(0.33 \mathrm{~g} \cdot \mathrm{L}^{-1}\right)$ and peptone $\left(1 \mathrm{~g} \cdot \mathrm{L}^{-1}\right)$ was supplemented into the fermentation media. Fermentation was carried out at $25^{\circ} \mathrm{C}$ and $200 \mathrm{rpm}$ for $120 \mathrm{~h}$ in a shaking incubator (Innova 4300, New Brunswick Scientific, NJ).

\subsection{Analysis of Sugars and Organic Acids}

Dry-cell weight (DCW) was used to determine cell concentrations. Cell pellets were washed with water two times, dried at $80^{\circ} \mathrm{C}$ overnight, and measured for weight. Sugars and organic acid concentrations were analyzed via a high-performance liquid chromatography (HPLC; Shimadzu Scientific Instruments, Inc., 
Columbia, MD, USA) equipped with a refractive index detector (RID) and a Rezex ROA organic acid column $(150 \times 7.8 \mathrm{~mm}$, Phenomenex Inc., Torrance, CA, USA). Oven temperature was kept at $80^{\circ} \mathrm{C}$, and $0.005 \mathrm{~N}$ sulfuric acid was utilized as a mobile phase, with a pumping rate of $1.0 \mathrm{~mL} \cdot \mathrm{min}^{-1}$.

\subsection{Yeast Cell Lysis and Lipid Extraction}

Yeast cells were harvested via centrifugation (Sorvall Super T21, Thermo Fisher Scientific Inc., Waltham, MA, USA) at $8500 \mathrm{rpm}$ for $20 \mathrm{~min}$. Cells were washed two times with water and concentrated to $10^{9}$ cells $\mathrm{mL}^{-1}$. The concentrated cells were preserved at $-80^{\circ} \mathrm{C}$ for one day prior to lipid extraction. Thawed cell pellets $(0.5 \mathrm{~mL})$ were transferred into a $2.5 \mathrm{~mL}$ polypropylene microvial, followed by adding $0.5 \mathrm{~mL}$ of methanol, $0.5 \mathrm{~mL}$ of chloroform, and $1 \mathrm{~mL}$ of $0.5 \mathrm{~mm}$ cubic zirconia beads. Bead beating was performed using a bead-beater homogenizer (Mini-Beadbeater-24, BioSpec Products, Inc., Bartlesville, OK, USA) in $45 \mathrm{sec}$ intervals, with a cooling of $10 \mathrm{~min}$ on ice repeated six times. Lipid extraction was conducted by following a modified Bligh and Dyer method [29]. The cell lysate after bead beating was transferred into a $7 \mathrm{~mL}$ Kimax tube, and chloroform: methanol:water were added with a ratio of 1:2:0.8, respectively. Tubes containing cell lysate mixtures were vortexed and centrifuged at $4000 \mathrm{rpm}$ for $20 \mathrm{~min}$. The lipid layer (bottom layer) of the mixture was transferred into a clean tube using a Pasteur pipette, and $1 \mathrm{~mL}$ of chloroform was added into the mixture followed by vortexing and centrifugation. Lipid extraction was repeated three times and the combined lipid layers were filtered using PTFE filters with $0.22 \mu \mathrm{M}$ pore size. The filtrates were washed two times with a $1 \mathrm{M}$ potassium chloride solution, followed by drying under nitrogen gas at $40^{\circ} \mathrm{C}$ until $1 \mathrm{ml}$ of mixture was left in the Kimax tube. The residue was transferred into a glass vial and dried down under nitrogen gas, again to completely remove chloroform and measure the lipid weight. After determination of lipid weights, $1 \mathrm{~mL}$ of chloroform was added into each glass vial and kept at $-80^{\circ} \mathrm{C}$ for further compositional analysis of the lipids. Lipid content in the yeast cells was determined by dividing weights of lipids from yeast cells by weights of concentrated cells. Cell weight was determined by measuring DCW of the concentrated cell.

\subsection{Analysis of Fatty Acid Composition}

Fatty acids in the lipids were converted to fatty acid methyl esters (FAMEs) via a transesterification for compositional analysis. Lipid samples were transferred into a $7 \mathrm{~mL}$ Kimax tube with $25 \mathrm{nmol}$ of internal standard (pentadecanoic acids) and the chloroform was evaporated under nitrogen gas at $40^{\circ} \mathrm{C}$. For transesterification, $1 \mathrm{~mL}$ of methanolic hydrochloric acid $(3 \mathrm{M})$ was added into each tube and incubated at $78^{\circ} \mathrm{C}$ for $30 \mathrm{~min}$ in the heating block. After cooling down the samples, $2 \mathrm{ml}$ of water were added, followed by $1.6 \mathrm{~mL}$ of chloroform and 0.4 $\mathrm{mL}$ of hexane. The layers were then separated via centrifugation at $4000 \mathrm{rpm}$ for $5 \mathrm{~min}$. The lower layer was transferred into a clean Kimax tube and the organic phase was dried down under nitrogen gas. One hundred $\mu \mathrm{L}$ of hexane were 
added to solubilize FAMEs, and then transferred into a glass vial. FAMEs were analyzed by injecting $1 \mu \mathrm{L}$ of the sample into a gas chromatograph (GC-2014, Shimadzu Scientific Instruments, Columbia, MD, USA) equipped with a flameionization detector (FID) and an aqueous-stable polyethylene glycol capillary column (Zebron ZB-Wax plus $30 \mathrm{~m} \times 0.25 \mathrm{~mm} \times 0.25 \mu \mathrm{m}$, Phenomenex, Torrance, $\mathrm{CA}, \mathrm{USA})$. The initial oven temperature of $160^{\circ} \mathrm{C}$ was gradually increased to $200{ }^{\circ} \mathrm{C}$ at a rate of $5{ }^{\circ} \mathrm{C} \mathrm{min}{ }^{-1}$, and detector temperature was $250^{\circ} \mathrm{C}$. The FAME mixture (Supelco, 37 component FAME mix) was utilized as an external standard to identify fatty acid composition in the lipids.

\subsection{Statistical Methods}

SAS software (SAS v9.4, SAS institute, Cary, NC, USA) was used to analyze all data by performing PROC GLM for the least-significant difference (LSD) test at a $95 \%$ confidence level $(P<0.05)$.

\section{Results and Discussion}

\subsection{Sugar Recoveries from Sorghum Stalks and Switchgrass}

The composition of ground sorghum stalks and switchgrass is shown in Figure 2. Sorghum stalks had a higher content of lignin (20\%) compared with switchgrass (16.9\%). Sorghum stalks contained three types of polysaccharides including $28.4 \%$ glucan, $19.4 \%$ xylan, and $1.7 \%$ arabinan. Switchgrass structure was $35 \%$ glucan and $29 \%$ xylan, containing higher amounts of total polysaccharides compared with sorghum stalks. Sorghum stalks and switchgrass were deconstructed using a $1.25 \%\left(\mathrm{w} \cdot \mathrm{v}^{-1}\right)$ sodium hydroxide solution, following the optimized conditions in the previous study [30]. Pretreated biomass totals of $58.6 \mathrm{~g}$ and $58.4 \mathrm{~g}$ were obtained from sorghum stalks and switchgrass, respectively. Alkaline pretreatment was utilized to effectively eliminate lignin compounds without significant loss of polysaccharides [11].

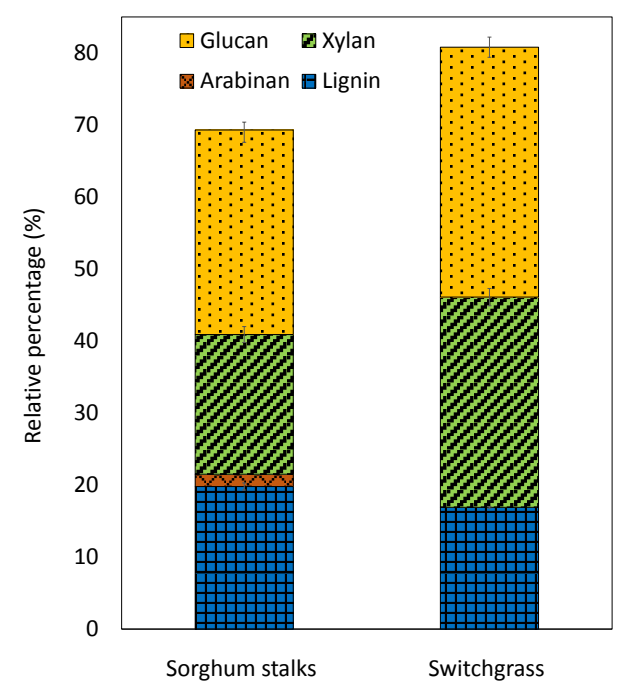

Figure 2. Composition of lignocellulosic biomass. The data shows average value of triplicate experiments and error bars representing sample standard deviation. 
After saccharification of each pretreated biomass, sugar recoveries from lignocellulosic biomass were investigated in Figure 3. Also, maximum theoretical yields of sugar recoveries were determined using a conversion factor of 0.9 from glucose to glucan, and 0.88 from xylose (arabinose) to xylan (arabinan) [27]. Figure 3(a) shows sugar yields released from $100 \mathrm{~g}$ of each lignocellulosic biomass. Totals of $29.8 \mathrm{~g}$.glucose, $17.8 \mathrm{~g}$ xylose, and $1.7 \mathrm{~g}$ arabinose were released from $100 \mathrm{~g}$ of raw sorghum stalks. This was $94 \%, 81 \%$, and $89 \%$ of maximum theoretical yields (TY) for glucose, xylose, and arabinose, respectively. Similar amounts of fermentable sugars were achieved from sorghum stalks and switchgrass, although they had a different content of polysaccharides. Total sugar yield from $100 \mathrm{~g}$ of switchgrass was $34 \mathrm{~g}$ of glucose and $15 \mathrm{~g}$ of xylose. Sugar recoveries from raw switchgrass were $88 \%$ and $45 \%$ of maximal TY for glucose and xylose, respectively. Even though switchgrass content showed higher amounts of polysaccharides, lower sugar recovery was obtained due to hemicellulose loss during pretreatment [31]. Xylose recovery was substantially low because harsher conditions were applied for pretreatment of switchgrass compared with sorghum stalks. Sugar yield from $100 \mathrm{~g}$ of each pretreated biomass is shown in Figure 3(b). Sugar yields of glucose, xylose, and arabinose from $100 \mathrm{~g}$ of pretreated sorghum stalks were $51 \mathrm{~g}, 30 \mathrm{~g}$, and $2.9 \mathrm{~g}$, respectively. Whereas, $58 \mathrm{~g}$ of glucose and $26 \mathrm{~g}$ of xylose were released from $100 \mathrm{~g}$ of switchgrass. In spite of higher content of xylan in switchgrass, xylose yield from pretreated biomass was lower than from sorghum stalks. This also reflects significant loss of hemicellulose during pretreatment. Total sugar yields from pretreated sorghum stalks and switchgrass were similar.

\subsection{Microbial Lipid Production from Lignocellulosic Hydrolysates}

Sorghum stalks and switchgrass hydrolysates were utilized as feedstocks for lipid production using T. oleaginosus, L. starkeyi, and C.albidus. Both lignocellulosic

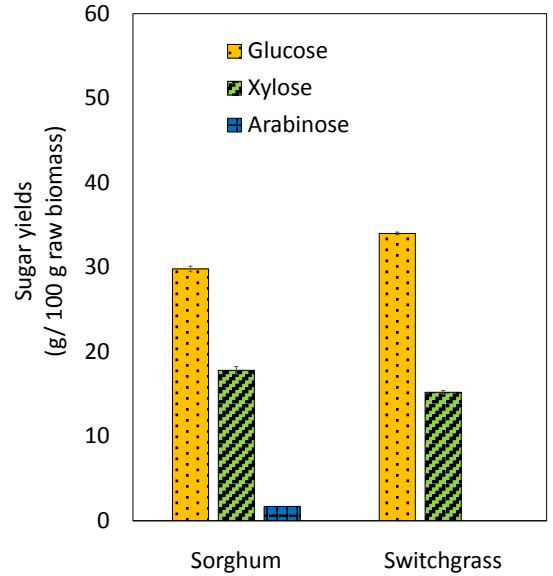

(a)

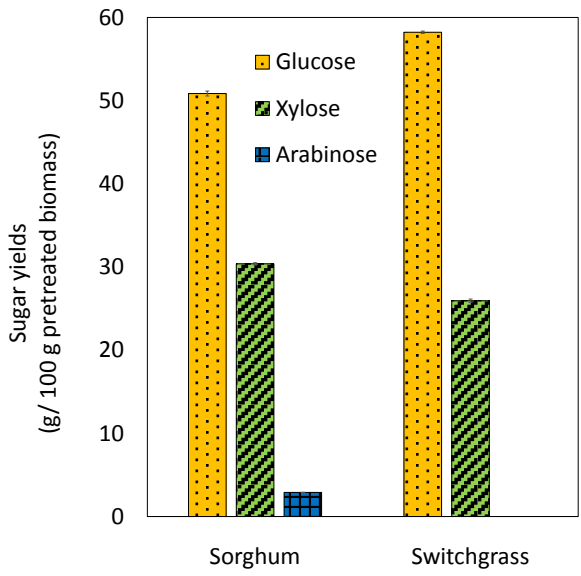

(b)

Figure 3. Sugar yield from (a) raw lignocellulosic biomass; (b) pretreated lignocellulosic biomass. The data show average value of triplicate experiments and error bars representing sample standard deviation. 
hydrolysates contained acetic acid and citric acid as byproducts of enzymatic hydrolysis process. Acetic acid is normally released from acetylated hemicellulose [19]. The reason why citric acid was contained in the hydrolysates seemed that citric acid was included during enzymatic hydrolysis process to maintain $\mathrm{pH}$. Figure 4 shows the fermentation profile of each oleaginous yeast using sorghum stalks and switchgrass hydrolysates.

Sugar consumption rate of $T$. oleaginosus was the fastest, compared with the other two strains. T. oleaginosus consumed all sugars in sorghum stalks and switchgrass hydrolysates at $72 \mathrm{~h}$. L. starkeyi consumed all glucose in the biomass hydrolysates at $72 \mathrm{~h}$, and started using xylose. C. albidus slowly consumed only glucose for $120 \mathrm{~h}$. Citrate utilization was only observed by $T$. oleaginosus. $T$. oleaginosus consumed a total of $6 \mathrm{~g} \cdot \mathrm{L}^{-1}$ citrate in both biomass hydrolysates after all glucose was utilized at $48 \mathrm{~h}$. L. starkeyi and C. albidus did not use citrate as nutrients. Instead of utilization, citrate accumulation was observed by $C$. albidus during lipid production. A total of $3 \mathrm{~g} \cdot \mathrm{L}^{-1}$ of citric acid was produced as a

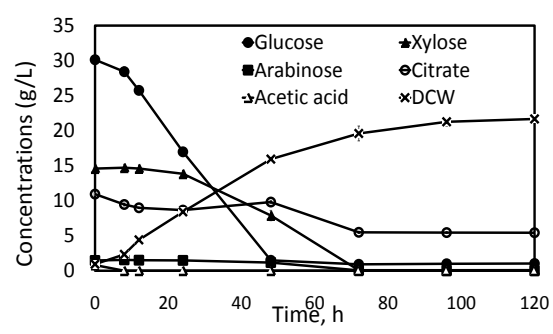

(a)

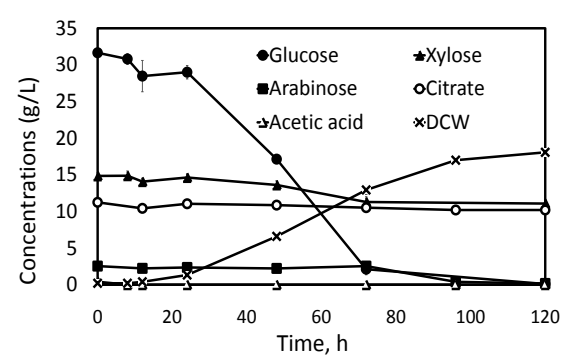

(c)

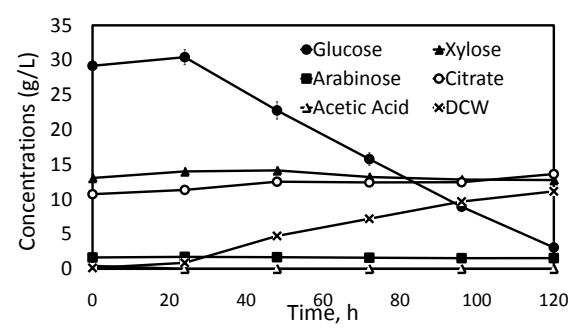

(e)

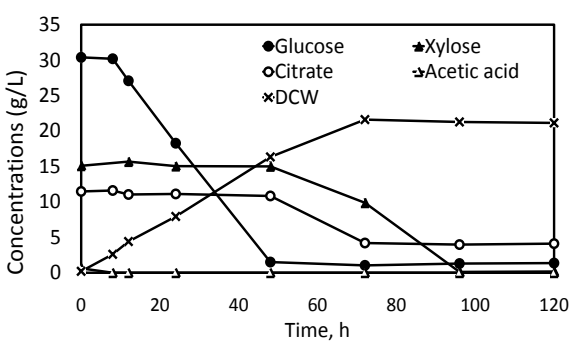

(b)

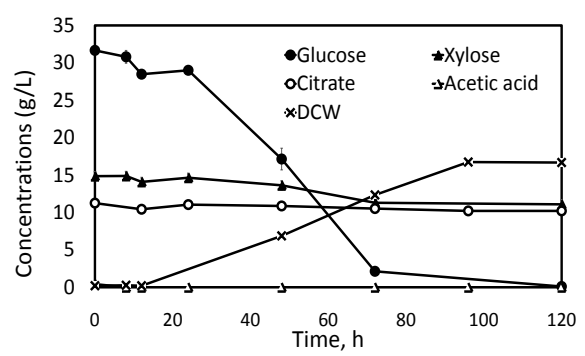

(d)

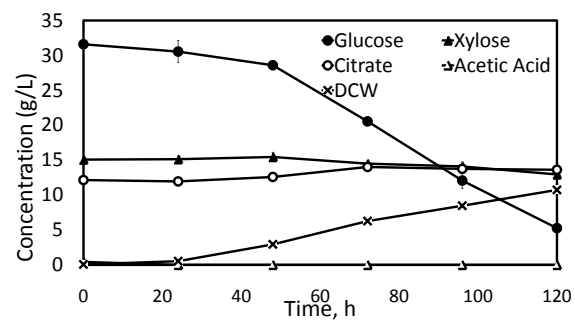

(f)

Figure 4. Fermentation profile during lipid production by (a) T. oleaginosus using sorghum stalk hydrolysates; (b) T. oleaginosus using switchgrass hydrolysates; (c) L. starkeyi using sorghum stalk hydrolysates; (d) L. starkeyi using switchgrass hydrolysates; (e) C. albidus using sorghum stalk hydrolysates; (f) C. albidus using switchgrass hydrolysates. The data show average value of triplicate experiments and error bars representing sample standard deviation. 
secondary metabolite. It is known that citric acid is an important substrate of ATP citrate lyase $(A C L)$ to improve lipid accumulation in oleaginous yeast; $A C L$ enzymes have responsibility to increase cytosolic Acetyl-CoA pool which is major substrate for lipid synthesis [32] [33] [34]. Therefore, it is assumed that consumption of citrate might play important roles for high lipid production of $T$. oleaginosus. As was our expectation, all strains utilized acetic acid as nutrients. Sorghum stalks and switchgrass hydrolysates contained $0.5 \mathrm{~g} \cdot \mathrm{L}^{-1}$ acetic acid and completely consumed by all yeast strains. Acetic acid consumption by oleaginous species was also consented with other studies [35] [36]. Table 1 shows fermentation performance of oleaginous yeast during lipid production using both lignocellulosic hydrolysates. T. oleaginosus showed the best performance of lipid production among oleaginous yeast strains. T. oleaginosus accumulated a total of $60 \%$ and $58 \%$ of lipids using sorghum stalk and switchgrass hydrolysates, respectively. Lipid content using sorghum stalk hydrolysates did not significantly differ from that using switchgrass hydrolysates at a 95\% confident level. Similar levels of DCW (about $21 \mathrm{~g} \cdot \mathrm{L}^{-1}$ ) were achieved from sorghum stalk and switchgrass hydrolysates. Although utilized sugar concentration of T. oleaginosus was higher in the switchgrass hydrolysates, higher lipid concentrations (13 $\left.\mathrm{g} \cdot \mathrm{L}^{-1}\right)$ were attained in the sorghum stalk hydrolysates.

A high lipid yield of $0.29 \mathrm{~g} \cdot \mathrm{g}^{-1}$ was obtained by $T$. oleaginosus using sorghum stalk hydrolysates. This product yield was a close value to the economically feasible lipid yield suggested by Lennen and F.Pfleger; $0.3-0.4 \mathrm{~g} \cdot \mathrm{g}^{-1}$ would be theoretical limit to replace current petrochemical technologies [37]. L. starkeyi also produced higher concentrations of lipids with higher lipid content in the sorghum stalk hydrolysates compared with switchgrass hydrolysates, and it was statistically different value at 95\% confident level. However, lower lipid yield was

Table 1. Fermentation parameters of oleaginous yeast during lipid production

\begin{tabular}{lccccc}
\hline & $\begin{array}{c}\text { a Lipid } \\
\text { content } \\
(\%)\end{array}$ & $\begin{array}{c}\text { Lipid } \\
\text { concentration } \\
\left(\mathrm{g} \cdot \mathrm{L}^{-1}\right)\end{array}$ & $\begin{array}{c}{ }^{\mathrm{b}} \text { Lipid yield } \\
\left(\mathrm{g} \cdot \mathrm{g}^{-1}\right)\end{array}$ & $\begin{array}{c}\text { Dry-cell } \\
\text { weight } \\
\left(\mathrm{g} \cdot \mathrm{L}^{-1}\right)\end{array}$ & $\begin{array}{c}\text { Sugar } \\
\text { consumption } \\
\left(\mathrm{g} \cdot \mathrm{L}^{-1}\right)\end{array}$ \\
\hline T. oleaginosus & $60 \pm 2.5^{\mathrm{A}}$ & $13.1 \pm 0.7^{\mathrm{A}}$ & $0.29 \pm 0.0^{\mathrm{A}}$ & $21.7 \pm 0.3^{\mathrm{A}}$ & $45 \pm 0.7^{\mathrm{B}}$ \\
L. starkeyi & $44 \pm 2.0^{\mathrm{B}}$ & $7.9 \pm 0.3^{\mathrm{C}}$ & $0.16 \pm 0.0^{\mathrm{C}}$ & $18.1 \pm 0.1^{\mathrm{B}}$ & $48 \pm 0.7^{\mathrm{A}}$ \\
C. albidus & $42 \pm 2.0^{\mathrm{B}, \mathrm{C}}$ & $4.6 \pm 0.2^{\mathrm{E}}$ & $0.17 \pm 0.0^{\mathrm{D}}$ & $11.1 \pm 0.1^{\mathrm{D}}$ & $27 \pm 0.6^{\mathrm{E}}$ \\
& & Switchgrass hydrolysates & & \\
T. oleaginosus & $58 \pm 2.6^{\mathrm{A}}$ & $12.3 \pm 0.2^{\mathrm{B}}$ & $0.27 \pm 0.0^{\mathrm{B}}$ & $21.1 \pm 0.6^{\mathrm{A}}$ & $46 \pm 1.1^{\mathrm{B}}$ \\
L. starkeyi & $39 \pm 0.1^{\mathrm{C}}$ & $6.5 \pm 0.3^{\mathrm{D}}$ & $0.17 \pm 0.0^{\mathrm{D}}$ & $16.6 \pm 0.4^{\mathrm{C}}$ & $38 \pm 0.9^{\mathrm{C}}$ \\
C. albidus & $44 \pm 0.0^{\mathrm{B}}$ & $4.7 \pm 0.1^{\mathrm{E}}$ & $0.16 \pm 0.0^{\mathrm{C}}$ & $10.7 \pm 0.3^{\mathrm{D}}$ & $29 \pm 1.4^{\mathrm{D}}$ \\
\hline
\end{tabular}

The data represent average value of triplicate experiments \pm sample standard deviation. Values with the same letters, in superscripts, within the same column, are not significantly different at a $95 \%$ confidence level. ${ }^{a}$ Lipid content was defined as weight of extractable lipid relative to weight of dry cell mass. ${ }^{\text {b Lipid yield }}$ was calculated by dividing amount of lipids by amount of sugar consumed. 
obtained in the sorghum stalk hydrolysates. It was because of that fewer amounts of sugars were consumed in the switchgrass hydrolysates. Results of statistical analysis showed that lipid accumulation of $C$. albidus was similar with L. starkeyi in the sorghum stalks hydrolysates, but $C$. albidus produced the lowest concentration of lipids in both biomass hydrolysates. This was because lower amounts of DCW were obtained using both biomass hydrolysates. These results demonstrated that both lipid content and DCW were important factors to achieve high titers of lipids by oleaginous yeast, because lipids are intracellular products.

Figure 5 shows the composition of fatty acids produced by oleaginous yeast cultures using sorghum stalks and switchgrass hydrolysates. To identify fatty acid profile of lipids, fatty acids were methylated to FAMEs via transesterification process and analyzed by injecting them into GC and GC/MS. Different species of fatty acids were produced by $T$. oleaginosus, L. starkeyi, and C. albidus. Major fatty acids of $T$. oleaginosus was oleic acid (C18:1), and this result was consistent with previous studies [27] [28]. Myristic acid (C14) was only produced by $T$. oleaginosus, but the amount was marginal. The most abundant fatty acid of $L$. starkeyi was also oleic acid, accounting for more than $60 \%$. Other studies also reported that L. starkeyi contented relatively high levels of oleic acid (up to 70\%),

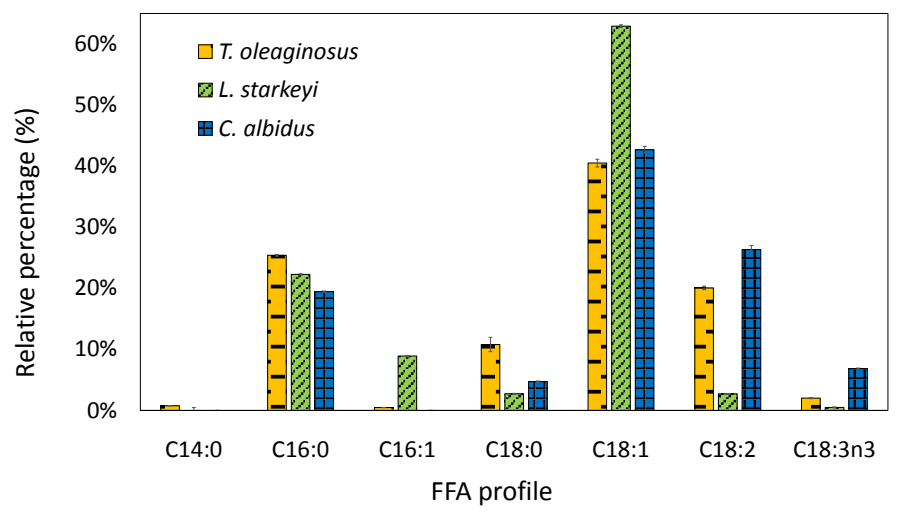

(a)

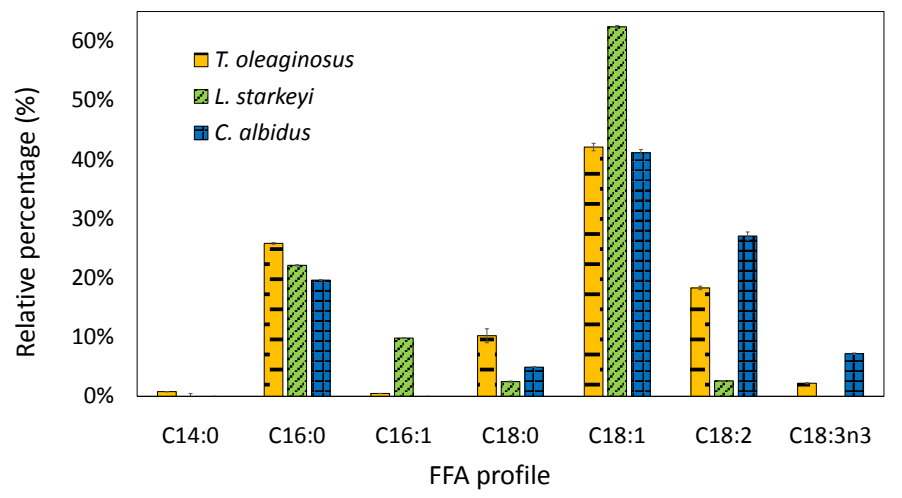

(b)

Figure 5. Composition of fatty acid produced from (a) sorghum stalk hydrolysates; (b) switchgrass hydrolysates. The data show average value of triplicate experiments and error bars representing sample standard deviation. 
which is preferable in the oleochemical industry [39] [40]. Oleic acid was a major fatty acid for all yeast strains because most yeast species include a $\Delta 9$ desaturase, which incorporates a double bond at $\Delta 9$ position of stearic acid or palmitic acid [4]. T. oleaginosus and C. albidus produced relatively higher levels of linoleic acid (C18:2n6) and linolenic acid (C18:3n3) compared with L. starkeyi. In addition, $L$. starkeyi did not produce linolenic acid. In the fatty acid elongation cycle, oleic acid can be further desaturated to linoleic acid and linolenic acid by $\Delta^{12}$ desaturase and $\omega^{3}$ desaturase, respectively [4]. It was assumed that $L$. starkeyi does not have $\omega^{3}$ desaturase, and $\Delta^{12}$ desaturase enzyme activity would be insignificant. Therefore, the highest amount of oleic acid, which is a substrate of both desaturase enzymes ( $\Delta^{12}$ desaturase and $\omega^{3}$ desaturase), was contented in the $L$. starkeyi. Also, it is anticipated that a desaturase enzyme produced by T. oleaginosus or C. albidus, can be utilized to develop microbial strains for polyunsaturated fatty acid production.

\subsection{Lipid Yield from Lignocellulosic Biomass}

Our bioconversion process of lignocellulose-based microbial lipid production was evaluated by calculating the overall yield of lipid from raw sorghum stalks and switchgrass (Figure 6). Type of lignocellulosic hydrolysate did not considerably affect lipid yields whereas species of yeast strains and their fermentation performance directly affected total lipid yield from sorghum stalks and switchgrass. It was due to that similar amount of sugars (about $49 \mathrm{~g}$ ) were recovered from $100 \mathrm{~g}$ of both biomasses, and similar fermentation performance was obtained from both biomass hydrolysates.

The highest lipid yield was achieved by $T$. oleaginosus from both lignocellulosic biomasses, since $T$. oleaginosus showed the best fermentation performance among other yeast strains during lipid production. T. oleaginosus produced $8 \%$ higher amounts of lipids from sorghum stalks containing a $14 \%$ lower con-

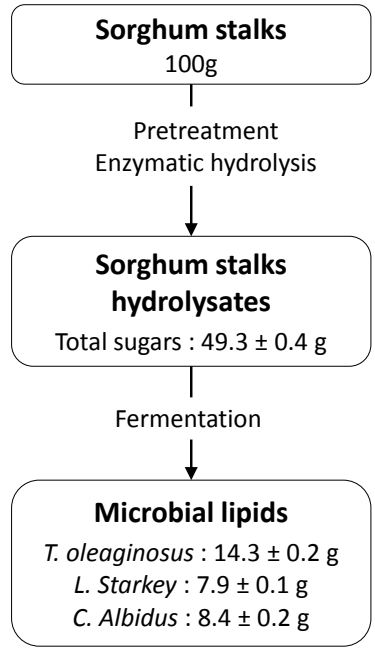

(a)

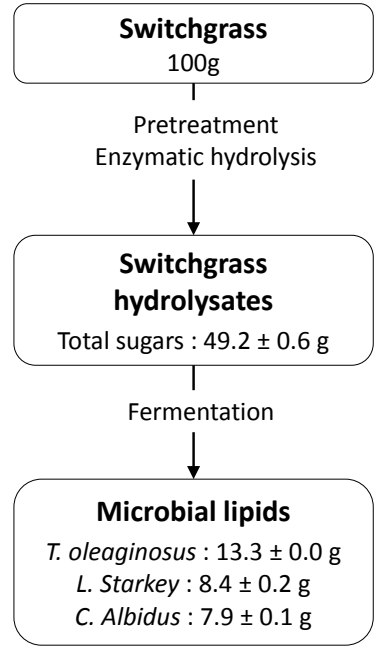

(b)

Figure 6. Lipid yields from (a) sorghum stalks; (b) switchgrass. The data represent average value of triplicate experiments \pm sample standard deviation. 
tent of polysaccharides compared with switchgrass. This might be due to a significant hemicellulose loss during pretreatment of switchgrass. It showed another key factor to attaining high lipid yields from biomass was to maximize sugar recoveries during pretreatment and enzymatic hydrolysis for sugar production.

Lipid yields obtained by $C$. albidus and $L$. starkeyi were not substantially different because they showed similar fermentation performance during lipid production. C. albidus produced higher amounts of lipids from sorghum stalks compared with switchgrass, although low-lipid concentrations were obtained during fermentation. It was due to that higher product yield was achieved during fermentation using sorghum stalk hydrolysates. Whereas, lower amounts of lipids were obtained by L. starkeyi using sorghum stalks compared with switchgrass, even though higher lipid concentrations and contents were attained during fermentation of L. starkeyi using sorghum stalk hydrolysates. This was because lower sugar consumptions and product yields were observed by L. starkeyi in sorghum stalk hydrolysates. To sum up these results, maximization of sugar recoveries during sugar production, and selection of proper microbial strains for lipid production, were key factors to achieve high yields of microbial lipids from lignocellulosic biomass.

\section{Conclusion}

Microbial lipid production from lignocellulosic biomass such as sorghum stalks and switchgrass was investigated using three oleaginous yeast strains; T. oleaginosus, L. starkeyi and C. albidus. High-sugar recoveries (89\% of TY) from sorghum stalks were obtained via an alkaline pretreatment whereas total sugar recoveries from switchgrass were $67 \%$ of the TY. T. oleaginosus showed the best fermentation performance using both biomass hydrolysates among oleaginous yeast cultures. Lipid titers of $13.2 \mathrm{~g} \cdot \mathrm{L}^{-1}$ and lipid yield of $0.29 \mathrm{~g} \cdot \mathrm{g}^{-1}$ were achieved by $T$. oleaginosus using sorghum stalk hydrolysates. Results of overall lipid yield assessment revealed that a key matrix to improve industrial feasibility of bioconversion for lignocelluose-based microbial lipid production is maximal recovery of fermentable sugars from raw biomass and strain development to attain better fermentation performance.

\section{Acknowledgements}

This work was funded by the Development Initiative Competitive Grants Program (BRDI; grant number: 2012-10008-20263). The authors are also grateful to Novozymes Inc. for the donation of enzyme samples, and Dr. Yadhu N. Guragain for his valuable suggestions on pretreatment process. Author PVV thanks the Lortscher Endowment for their support.

\section{References}

[1] Mazzobre, M.F., Roman, M.V., Mourelle, A.F. and Corti, H.R. (2005) Octanol-Water Partition Coefficient of Glucose, Sucrose, and Trehalose. Carbohydrate Resource, 340, 1207-1211. 
[2] Krishnakumar, U. and Sivasubramanian, V. (2016) Optimization of Lab-Scale Preparation of Biodiesel from Rubber Seed Oil Using Modified Calcium Oxide as Catalyst. Journal of Sustainable Bioenergy Systems, 6, 55-65. https://doi.org/10.4236/jsbs.2016.63006

[3] Suh, J.W., Lee, S.H. and Chung, B.C. (1997) GC-MS Determination of Organic Acids with Solvent Extraction after Cation-Exchange Chromatography. Clinical Chemistry, 43, 2256-2261.

[4] Wu, H., Lee, J., Karanjikar, M. and San, K. (2014) Efficient Free Fatty Acid Production from Woody Biomass Hydrolysate Using Metabolically Engineered Escherichia coli. Bioresource Technology, 169, 119-125.

[5] Singh, S., Gamlath, S. and Wakeling, L. (2007) Nutritional Aspects of Food Extrusion: A Review. International Journal of Food Science and Technology, 42, 916-929. https://doi.org/10.1111/j.1365-2621.2006.01309.x

[6] Rodrigues, T.H.S., de Barros, E.M., de Sá Brígido, J., da Silva, W.M., Rocha, M.V.P. and Gonçalves, L.R.B. (2016) The Bioconversion of Pretreated Cashew Apple Bagasse into Ethanol by SHF and SSF Processes. Applied Biochemistry and Biotechnology, 178, 1167-1183. https://doi.org/10.1007/s12010-015-1936-0

[7] Breitenbach, J. (2002) Melt Extrusion: From Process to Drug Delivery Technology. European Journal of Pharmaceutics and Biopharmaceutics, 54, 107-117.

[8] Darvekar, P. and Holtzapple, M.T. (2016) Assessment of Shock Pretreatment of Corn Stover Using the Carboxylate Platform. Applied Biochemistry and Biotechnology, 178, 1081-1094. https://doi.org/10.1007/s12010-015-1930-6

[9] Pratto, B., de Souza, R.B.A., Sousa Jr., R. and da Cruz, A.J.G. (2016) Enzymatic Hydrolysis of Pretreated Sugarcane Straw: Kinetic Study and Semi-Mechanistic Modeling. Applied Biochemistry and Biotechnology, 178, 1430-1444. https://doi.org/10.1007/s12010-015-1957-8

[10] Amirsadeghi, M., Shields-Menard, S., French, W.T. and Hernandez, R. (2015) Lipid Production by Rhodotorula glutinis from Pulp and Paper Wastewater for Biodiesel Production. Journal of Sustainable Bioenergy Systems, 5, 114-125. https://doi.org/10.4236/jsbs.2015.53011

[11] Bondeson, D. and Oksman, K. (2007) Polylactic Acid/Cellulose Whisker Nanocomposites Modified by Polyvinyl Alcohol. Composites Part A: Applied Science and Manufacturing, 38, 2486-2492.

[12] Smith, M.A., Moon, H., Chowrira, G. and Kunst, L. (2003) Heterologous Expression of a Fatty Acid Hydroxylase Gene in Developing Seeds of Arabidopsis thaliana. Planta, 217, 507-516. https://doi.org/10.1007/s00425-003-1015-6

[13] Holic, R., Yazawa, H., Kumagai, H. and Uemura, H. (2012) Engineered High Content of Ricinoleic Acid in Fission Yeast Schizosaccharomyces pombe. Applied Microbiology and Biotechnology, 95, 179-187. https://doi.org/10.1007/s00253-012-3959-6

[14] Carvalho, C.W.P. and Mitchell, J.R. (2000) Effect of Sugar on the Extrusion of Maize Grits and Wheat Flour. International Journal of Food Science and Technology, 35, 569-576. https://doi.org/10.1111/j.1365-2621.2000.00454.x

[15] Chen, X., Zhang, Y., Gu, Y., Liu, Z., Shen, Z., Chu, H. and Zhou, X. (2014) Enhancing Methane Production from Rice Straw by Extrusion Pretreatment. Applied Energy, 122, 34-41.

[16] Choi, C.H. and Oh, K.K. (2012) Application of a Continuous Twin Screw-Driven Process for Dilute Acid Pretreatment of Rape Straw. Bioresource Technology, 110, 349-354. 
[17] Dalli, S.S., da Silva, S.S., Uprety, B.K. and Rakshit, S.K. (2017) Enhanced Production of Xylitol from Poplar Wood Hydrolysates through a Sustainable Process Using Immobilized New Strain Candida tropicalis UFMG BX 12-a. Applied Biochemistry and Biotechnology, 1-12. https://doi.org/10.1007/s12010-016-2381-4

[18] Arora, N., Patel, A., Pruthi, P.A. and Pruthi, V. (2016) Boosting TAG Accumulation with Improved Biodiesel Production from Novel Oleaginous Microalgae Scenedesmus sp. IITRIND2 Utilizing Waste Sugarcane Bagasse Aqueous Extract (SBAE). Applied Biochemistry and Biotechnology, 180, 109-121. https://doi.org/10.1007/s12010-016-2086-8

[19] Karunanithy, C., Muthukumarappan, K. and Gibbons, W.R. (2012) Extrusion Pretreatment of Pine Wood Chips. Applied Biochemistry and Biotechnology, 167, 8199. https://doi.org/10.1007/s12010-012-9662-3

[20] Yoo, J., Alavi, S., Vadlani, P. and Behnke, K.C. (2012) Soybean Hulls Pretreated Using Thermo-Mechanical Extrusion-Hydrolysis Efficiency, Fermentation Inhibitors, and Ethanol Yield. Applied Biochemistry and Biotechnology, 166, 576-589. https://doi.org/10.1007/s12010-011-9449-y

[21] Duque, A., Manzanares, P., Ballesteros, I., Negro, M.J., Oliva, J.M., Gonzalez, A. and Ballesteros, M. (2014) Sugar Production from Barley Straw Biomass Pretreated by Combined Alkali and Enzymatic Extrusion. Bioresource Technology, 158, 262-268.

[22] Liu, L., Hu, Y., Lou, W., Li, N., Wu, H. and Zong, M. (2016) Use of Crude Glycerol as Sole Carbon Source for Microbial Lipid Production by Oleaginous Yeasts. Applied Biochemistry and Biotechnology, 1-16. https://doi.org/10.1007/s12010-016-2340-0

[23] Rosentrater, K.A. and Muthukumarappan, K. (2006) Corn Ethanol Coproducts: Generation, Properties, and Future Prospects. International Sugar Journal, 108, 648-657.

[24] Spiehs, M.J., Whitney, M.H. and Shurson, G.C. (2002) Nutrient Database for Distiller's Dried Grains with Solubles Produced from New Ethanol Plants in Minnesota and South Dakota. Journal of Animal Science, 80, 2639-2645. https://doi.org/10.2527/2002.80102639x

[25] Hoover, S.W., Youngquist, J.T., Angart, P.A., Withers, S.T., Lennen, R.M. and Pfleger, B.F. (2012) Isolation of Improved Free Fatty Acid Overproducing Strains of Escherichia coli via Nile Red Based High-Throughput Screening. AIChE Annual Meeting, 31, 17-23. https://doi.org/10.1002/ep.10599

[26] Risenberg, D. (1991) High-Cell-Density Cultivation of Escherichia coli. Current Opinion in Biotechnology, 2, 380-384.

[27] Kim, K. and Oh, D. (2013) Production of Hydroxy Fatty Acids by Microbial Fatty Acid-Hydroxylation Enzymes. Biotechnology Advances, 31, 1473-1485.

[28] Guragain, Y.N., Bastola, K.P., Madl, R.L. and Vadlani, P.V. (2016) Novel Biomass Pretreatment Using Alkaline Organic Solvents: A Green Approach for Biomass Fractionation and 2,3-Butanediol Production. BioEnergy Research, 9, 643-655. https://doi.org/10.1007/s12155-015-9706-y

[29] Uemura, H. (2012) Synthesis and Production of Unsaturated and Polyunsaturated Fatty Acids in Yeast: Current State and Perspectives. Applied Microbiology and Biotechnology, 95, 1-12. https://doi.org/10.1007/s00253-012-4105-1

[30] Meesapyodsuk, D. and Qiu, X. (2008) An Oleate Hydroxylase from the Fungus Claviceps purpurea: Cloning, Functional Analysis, and Expression in Aarabidopsis. Plant Physiology, 147, 1325-1333. https://doi.org/10.1104/pp.108.117168

[31] Lee, J., Guragain, Y.N., Bastola, K.P. and Vadlani, P.V. (2016) Innovative Methods 
to Generate Clean Sugar Stream from Biomass Feedstocks for Efficient Fermentation. Bioprocess and Biosystems Engineering, 1-9.

[32] Probst, K.V., Schulte, L.R., Durrett, T.P., Rezac, M.E. and Vadlani, P.V. (2016) Oleaginous Yeast: A Value-Added Platform for Renewable Oils. Critical Reviews in Biotechnology, 36, 942-955. https://doi.org/10.3109/07388551.2015.1064855

[33] Zhang, H., Zhang, L., Chen, H., Chen, Y.Q., Chen, W., Song, Y. and Ratledge, C. (2014) Enhanced Lipid Accumulation in the Yeast Yarrowia lipolytica by OverExpression of ATP: Citrate Lyase from Mus musculus. Journal of Biotechnology, 192, 78-84.

[34] Dulermo, T., Lazar, Z., Dulermo, R., Rakicka, M., Haddouche, R. and Nicaud, J. (2015) Analysis of ATP-Citrate Lyase and Malic Enzyme Mutants of Yarrowia lipolytica Points out the Importance of Mannitol Metabolism in Fatty Acid Synthesis. Biochimica et Biophysica Acta, 1851, 1107-1117.

[35] Slininger, P.J., Dien, B.S., Kurtzman, C.P., Moser, B.R., Bakota, E.L., Thompson, S.R., O'Bryan, P.J., Cotta, M.A., Balan, V. and Jin, M. (2016) Comparative Lipid Production by Oleaginous Yeasts in Hydrolyzates of Lignocellulosic Biomass and Process Strategy for High Titers. Biotechnology and Bioengineering, 113, 16761690. https://doi.org/10.1002/bit.25928

[36] Béligon, V., Poughon, L., Christophe, G., Lebert, A., Larroche, C. and Fontanille, P. (2016) Validation of a Predictive Model for Fed-Batch And Continuous Lipids Production Processes from Acetic Acid Using the Oleaginous Yeast Cryptococcus curvatus. Biochemical Engineering Journal, 111, 117-128.

[37] Kourist, R., Bracharz, F., Lorenzen, J., Kracht, O.N., Chovatia, M., Daum, C., Deshpande, S., Lipzen, A., Nolan, M., Ohm, R.A., Grigoriev, I.V., Sun, S., Heitman, J., Brueck, T. and Nowrousian, M. (2015) Genomics and Transcriptomics Analyses of the Oil-Accumulating Basidiomycete Yeast Trichosporon oleaginosus. Insights into Substrate Utilization and Alternative Evolutionary Trajectories of Fungal Mating Systems. mBio, 6, e00918-15.

[38] Tchakouteu, S.S., Chatzifragkou, A., Kalantzi, O., Koutinas, A.A., Aggelis, G. and Papanikolaou, S. (2015) Oleaginous Yeast Cryptococcus curvatus Exhibits Interplay between Biosynthesis of Intracellular Sugars and Lipids. European Journal of Lipid Science and Technology, 117, 657-672. https://doi.org/10.1002/ejlt.201400347

[39] Jaworski, J. and Cahoon, E.B. (2003) Industrial Oils from Transgenic Plants. Current Opinion in Plant Biology, 6, 178-184.

[40] Probst, K.V. and Vadlani, P.V. (2015) Production of Single Cell Oil from Lipomyces starkeyi ATCC 56304 Using Biorefinery By-Products. Bioresource Technology, 198, 268-275. 
Submit or recommend next manuscript to SCIRP and we will provide best service for you:

Accepting pre-submission inquiries through Email, Facebook, LinkedIn, Twitter, etc. A wide selection of journals (inclusive of 9 subjects, more than 200 journals)

Providing 24-hour high-quality service

User-friendly online submission system

Fair and swift peer-review system

Efficient typesetting and proofreading procedure

Display of the result of downloads and visits, as well as the number of cited articles Maximum dissemination of your research work

Submit your manuscript at: http://papersubmission.scirp.org/

Or contact jsbs@scirp.org 